\title{
Analysis of Sharing Vehicle Infringement under the Background of Sharing of Traffic Patterns
}

\author{
ZhouShuChao $^{1, \text { a }} \mathrm{HuBo}^{2, \mathrm{~b}}$ \\ ${ }^{1}$ College of Law, Sichuan Agricultural University, Yan An, Sichuan, 625000 China \\ ${ }^{2}$ College of Finance, NANCHANG University, Nan Chang, Jiangxi,330100 China \\ a1003750070@126.com b1805873011@qq.com
}

Keywords: Sharing of traffic patterns, Sharing vehicle infringement, Responsibility issues.

\begin{abstract}
With the rapid development of urbanization and vehicle industry, traffic flow increases rapidly, resulting in a series of problems such as traffic jam, parking, air pollution and so on. Among them, traffic congestion has gradually caused the deepest feeling, the biggest impact, the most grudges, to the general public. If this problem is not effectively resolved and fundamentally governed, it will become a bottleneck restricting the development of urban economy and the improvement of people's living standards. Under this background, this paper probes into the problem of Sharing vehicle infringement under the background of Sharing of traffic patterns.
\end{abstract}

\section{Introduction}

With the rapid development of urbanization and vehicle industry, traffic flow increases rapidly, resulting in a series of problems such as traffic jam, parking, air pollution and so on. Among them, traffic congestion has gradually caused the deepest feeling, the biggest impact, the most grudges, to the general public. If this problem is not effectively resolved and fundamentally governed, it will become a bottleneck restricting the development of urban economy and the improvement of people's living standards. "Vehicle sharing" program in the United States, Canada, Europe and other countries flourished, the number of members soaring. The number of members close to 100,000 people in the United States, while the Netherlands capital Amsterdam's has 310 shared vehicle docking stations. "Vehicle sharing" in the future may become the day-to-day use of vehicles, which is cheaper than the traditional car rental business, more flexible and convenient to use than traditional ones. In China, due to traffic congestion, parking difficulties and other problems, the purchase of vehicles are faced more and more restrictions, and the cost of vehicles are also rising year after year, coupled with the big cities face air pollution problems and urgent, "vehicle sharing" in this context appears to be obvious advantage. It can not only reduce the number of vehicles used, save valuable land resources, but also alleviate traffic congestion and parking space shortages. And to a certain extent, replace the limit of car numbers, which is very suitable for big cities, such as Beijing, Shanghai, Guangzhou. However, "vehicle sharing" still faces many problems both at home and abroad. For example, when a car accident occurs after renting a vehicle, how does the responsibility of both sides divide? How to take responsibility for car rental when the vehicle is damaged in use? How to ensure that the member can use the vehicle anytime and anywhere? In addition to, because of the problem of Chinese society, the sharing of vehicles still faces the problem of trust. However, I believe that with the development of society and technology, "vehicle sharing" will become an important way for people to travel.

\section{Sharing of traffic patterns}

Sharing traffic is a kind of transportation system which is different from public transportation, but is similar to public transport, and is used for common and shared transportation, and the users who share traffic have no right to use the vehicles. The sharing of traffic can be used as an individual means of transportation, and it can improve the overall efficiency through common use, which is a kind of sustainable traffic mode. The traditional shared traffic mode includes vehicle sharing and 
vehicle sharing. Sharing traffic has begun early in the 1940 's Europe, the reason is mainly due to small vehicles have just been on the market with high price, but the sharing of a car between neighbors can save costs. The prosperity of the shared traffic in recent years is mainly attributed to high oil prices, parking and congestion in central cities, and increasing awareness of environmental protection. The biggest function of sharing traffic is to improve the efficiency of transportation by means of common transportation, reduce the parking space of facilities, and improve the economy while reducing the overall energy consumption emission. Vehicle sharing can better meet a reasonable number of small vehicle travel, by sharing the form of vehicles to reduce the ownership of small vehicles and reduce vehicle dependence. According to Zipcar's operating data, an average of 20 private vehicles can be replaced by each shared vehicle, in addition, 32\% of Zipcar's members having sold existing vehicles, 39\% members postponing the purchase plan, as a result, reducing the mileage of $79.8 \%$, mitigating the parking, congestion and other issues, even encourage more use of slow traffic mode, such as public transport and vehicles. Similarly, vehicle sharing, due to its basic daily usage rate of up to 10 times/car/day, has become an effective public transport supplement mode by providing door-to-door traffic services.

\section{"Vehicle sharing"}

"Vehicle sharing" is a kind of innovative traffic between private cars and public transport modes, originated in Switzerland and Germany, and later gradually emerged in the United States, Canada, Singapore, Japan and other countries. "Vehicle sharing" is the common use of a car, which is "public private vehicles". People have access to vehicles, with no ownership, which is similar to a short time rental car, but the formalities are simpler than renting a car. Only through the telephone, network, mobile phone, can you use the vehicle. "Vehicle sharing" is typically provided by an organization with a wide variety of vehicles to its members for vehicle use, which is paid according to the time and mileage used by the vehicle. So, for short trips in cities, "car sharing" is more cost-effective and convenient than renting a car or taking a taxi.

Table 1 Global development of the sharing traffic

\begin{tabular}{|l|l|l|l|}
\hline Types & Numbers & Promoting Cities & Typical cases \\
\hline Vehicle sharing & 43,500 & 600 & Zipcar, Autolib, City-carshare \\
\hline Vehicle sharing & 117,000 & 165 & Velib \\
\hline
\end{tabular}

Table 2 Major domestic vehicle sharing projects

\begin{tabular}{|l|l|l|l|}
\hline No. & City & project & Car Number \\
\hline 1 & Hangzhou & 5 & 93000 \\
\hline 2 & Wuhan & 2 & 92000 \\
\hline 3 & Shanghai & 3 & 21000 \\
\hline 4 & Zhuzhou & 1 & 20000 \\
\hline 5 & Taiyuan & 1 & 20000 \\
\hline 6 & Suzhou & 3 & 16150 \\
\hline 7 & Guangzhou & 1 & 15000 \\
\hline 8 & Taizhou & 2 & 13000 \\
\hline 9 & Shenzheng & 3 & 12400 \\
\hline
\end{tabular}




\begin{tabular}{|l|l|l|l|}
\hline 10 & Beijing & 3 & 11650 \\
\hline 11 & Xi'an & 2 & 10100 \\
\hline
\end{tabular}

In the use of sharing vehicles, the problem of uneven travel is neglected, and the arrival law of the passenger flow with sharing vehicle is the Parameters $\lambda$, that is to say, the negative exponential distribution of the user's successive arrival interval obeys the parameter as $\lambda$; the vehicle is selected and started to use until the vehicle returns to the parking lot time for the vehicle's service time, the vehicle service time obeys the parameter $\mu$ 's negative exponential distribution, in this process each share vehicle's work is independent, does not engage in the cooperation, and each share vehicle average service rate is equal. The average service rate of the whole shared Vehicle service system is $n \mu$. The service intensity of the system is $\rho=\lambda / n \mu<1$, based on the theory of queuing theory, the system in the process has $\mathrm{C}(\mathrm{c}=0,1 \ldots)$ users probability:

$$
\begin{aligned}
& P_{0}=\left[\sum_{k=0}^{k-1} \frac{1}{k !}\left(\frac{\lambda}{\mu}\right)^{k}+\frac{1}{n !} \cdot \frac{1}{1-\rho} \cdot\left(\frac{\lambda}{\mu}\right)^{n}\right]^{-1} \\
& P_{c}= \begin{cases}\frac{1}{c !}\left(\frac{\lambda}{\mu}\right)^{c} P_{0} & (c \leq n) \\
\frac{1}{n ! n^{c-n}}\left(\frac{\lambda}{\mu}\right)^{c} P_{0} & (c>n)\end{cases}
\end{aligned}
$$

Among them, in the condition of only $\mathrm{n}$ vehicle sharing, when the number of users in the system is $\mathrm{cn}$, the user can take the vehicle directly without queuing; When $\mathrm{c}>\mathrm{n}$, there are $\mathrm{n}-\mathrm{c}$ users who need to wait. According to the calculation of vehicle use probability in different time slots, the demand for shared vehicles and the high and low peaks of vehicle use can be obtained.

Multi-car parking lots equilibrium probability model: There is $\xi$ car parking lot $\mathrm{N}=\mathrm{m} / \Phi(\xi), \Phi(\xi)$ is the possibility of $\xi$ car in the car park. In this model, there are $\mathrm{n}$ car-free shared vehicles, parking lot $\mathrm{M}$ is distinguishable, the number of vehicles in each car park is random, the number of vehicles in the parking lot is distributed:

$$
W=\frac{(m+n-1) !}{(m-1) ! n !}
$$

According to Sterling formula:

$\ln n !=n \ln n-\mathrm{n}$, making $\eta=\mathrm{n} / \mathrm{m}$.

The logarithm of the permutation combination number is called entropy, and the entropy of the car parking arrangement is represented by $\mathrm{S}$.

$S=\ln W=m[(\eta+1) \ln (\eta+1)-\eta \ln \eta]$

Using the Lagrange formula to replace the entropy in the formula (5) is:

$\mathrm{F} \xi=\mathrm{m}[(\xi+1) \ln (\xi+1)-\xi \ln \xi]+\beta^{\prime} \quad[\mathrm{n}-\mathrm{N} \xi \Phi]+\alpha[\mathrm{m}-\mathrm{N} \Phi(\xi)]$

In the formula: Lagrange multiplier of $\beta$-shared vehicle number and Lagrange multiplier of $\alpha$-parking number.

Make $\partial \mathrm{F}(\xi) / \partial \xi=0$,then:

mə $[(\xi+1) \ln (\xi+1)-\xi \ln \xi] / \partial \xi=\operatorname{mln}^{\xi+1} / \xi$

That is $: \ln \xi+1 / \xi-\beta^{\prime} \mathrm{N} \Phi(\xi)=0$

Thus: $\Phi(\xi)=\beta^{-1} \ln (1+1 / \xi)$

Among them: $\beta^{\prime}=\beta \mathrm{L} / \mathrm{N}$ 
Without any traffic induction and navigation (i.e. completely random) conditions, the probability of vehicle number in the parking lot is shown in Figure 1:

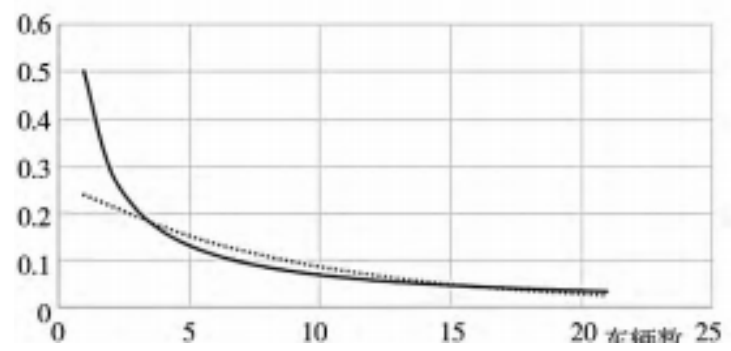

Figure 1 Probability of vehicle number in parking lot

\section{Analysis of Sharing vehicle infringement under the background of Sharing of traffic patterns}

(1) Legal issues of private ownership of shared bicycles. Since the launch of sharing bicycles, the idea is to share resources to facilitate public travel. However, in the convenient use, the sharing of bicycles frequently have been disorderly put, damaged, hidden, discarded and other chaotic occurrences, which has become a focus of social attention. For this problem, the author will expound the legal responsibility of the private share-sharing bicycle from civil, administrative and criminal liability respectively. From the civil liability, the indiscriminate possession and destruction of shared bicycles actually infringes on the ownership of shared bicycles by the operating parties according to article 2nd and 3rd of the Tort Liability Act. The shared cycling operator may claim damages for damages caused by the infringer, or may claim damages under article 34th to 38 of the Real Rights Act. In the case of private ownership of bicycles, it was also argued that the lawful possession of the vehicle by the user was obtained only during the actual lease, and the lawful possession of the shared bike was time-locked. If the user takes the bike as their own by locking the bike, he or she has infringed the ownership the bike, under which circumstances the owner may claim the right to ask the possession back. From the administrative responsibility to say, according to the article $49^{\text {th }}$ of the Law of Public Security Management Punishment, theft, fraud, looting, extortion or wilful destruction of public and private property is held, the detention of the following 5 to 10 days together with a fine of 500 Yuan; the heavier circumstances, the detention of the following 10 to 15 days, with a fine of 1000 yuan, which may be imposed on the perpetrator with a fine or administrative detention. Finally, in terms of criminal responsibility, if the number of users to steal, large or multiple theft of shared bicycles is large, in accordance with the provisions of article No. 264 of the Criminal Code, has resulted in criminal penalties for theft.

(2) The situation of renting and borrowing motor vehicles. The use of motor vehicles is generally rented in two cases, one is the rental of motor vehicles that do not provide driving services, that is, the leasing operator shall, within the agreed time, delivering the leased motor vehicle to the lessee for use, in order to collecting the rental fee. And the other one is providing the motor vehicle rental together with the driving service, that is, the leasing operator agrees with the lessee to provide the leased motor vehicle and the driving service, the lessee delivering the rent. Motor vehicle borrowing refers to the owner of the motor vehicle borrowing his or her vehicle to the lessee in the agreed time. Article 49th of the Tort Liability Act stipulates that: when the motor vehicle owner and the user are not the same person for the purpose of leasing or borrowing, after the traffic accident, the responsibility belongs to the motor Vehicle party liability, the insurance company in the motor vehicle bear the compulsory insurance liability limits within the scope of compensation. Insufficient part, the motor vehicle user undertakes the liability for compensation; the owner of the motor vehicle shall bear the corresponding liability for the fault of the occurrence of the damage. Tort Liability Act provides the first case of rental motor vehicle traffic accident occurred in the main body of the confirmation. As for the second case, although the name of the motor vehicle rental, in fact, to provide motor vehicle contract contract, the so-called "lessee" neither the operating interests of motor vehicles can not be dominated, so the owner of the motor vehicle is still machine Car rental company. When the "leased" 
motor vehicle traffic accidents caused by damage, by the motor vehicle as a "owner" of the leasing company to take responsibility. Of course, the leasing company is responsible for the employer's responsibility arising from his employment relationship with the driver, that is, his employees. In practice, the subject of responsibility under this situation is not controversial. For the first case, that is, only the provision of rental vehicles without driving services, during the car rental during the occurrence of traffic accidents how to confirm the main body of liability, in the Tort Liability Law before the introduction of controversy. One view is that the lender, the lessor should be regarded as the "guarantor" of the vehicle to bear the liability; another view that the lessor of the motor vehicle and the user jointly bear joint and several liability, if the lessor for the occurrence of damage Fault, after the compensation has the right to the lessee to recover. There is also a view that, in principle, the lessee should bear the liability of their own, but the lessor for the occurrence of damage with the fault should be with the lessee to bear joint and several liability for traffic accidents. According to the above "operating domination" and "operating interest" two criteria, leasing, borrowing motor vehicle traffic accident, the main responsibility should be in fact the direct control of the domination, and enjoy the operating interests of the lessee, borrowers, as to Scholars believe that the lessor through the rent of the collection and enjoy the operating interests of the motor vehicle is therefore the owner, bear the responsibility of the accident damage point of view, the author can not agree, because the lessor with the motor vehicle rental has lost the facts of the motor vehicle Control and domination, the rental income is only the tenant with the tenant to establish the relationship between the interests of the lease, rather than directly from the operation of the motor vehicle interests, as the lender, with the motor vehicle loans, motor vehicles Of the control and operating interests have been transferred to the borrower. Therefore, the main body of the motor vehicle traffic accident should be the lessee, borrowers. "Tort Liability Law" in the tenant, borrowers responsibility at the same time, standing in the fault of the legislative thinking of the provisions of the motor vehicle owners in the occurrence of damage to the fault, bear the fault of the corresponding liability. The provisions of the rule is based on the principle of no fault to establish the responsibility of the main body, that is, there is no limit to the scope of the application of motor vehicle traffic accident is not limited, not all subjects are applicable without fault liability, usually only motor vehicle Talent applicable. For the lessor of the lessor, the lender, it only bear the fault with the appropriate compensation. And the so-called fault, refers to the motor vehicle owners do not have the necessary attention obligations, such as knowing or should know that lend or rent a motor vehicle has some flaws, or know or should know the borrower, the tenant driving without a license, etc. In the causal relationship on the occurrence of traffic accident damage to play a certain role.

\section{References}

[1] Xuemei Xiao, Limin Jia. Evaluation model of connected reliability of urban rail transit network [J]. China Railway Science, 2016, 01:132-137.

[2] Xiaolong Li, Jinru Han, Liuyang Song. Study on the calculation method of design carrying capacity of urban rail transit network system [J]. Urban rail transit Research, 2016, 02:71-75.

[3] Zhipeng Wang, Yuanping Wu. Dynamic bottleneck identification method for urban rail transit network [J]. College Journal of Chang'an University (Natural Science Edition), 2015, S1:198-202.

[4] Tuo Shen, Yixin Pan, Qi Deng. Research on lifting method of transportation capacity of urban rail transit based on train distance measurement [J]. Urban rail Transit Research, 2015, 08:111-115.

[5] Chaoqun Wu, Yvlong Pei, Jingpeng Gao. Analysis of Urban rail transit network traffic supply and demand regulation capacity [J]. Journal of Wuhan University of Technology (Traffic Science and Engineering Edition), 2017, 01:22-26+31. 